\title{
Kesirler Konusunun Görsel Materyal ile Öğretiminin İlkokul 4. Sınıf Öğrencilerinin Matematik Başarı ve Tutumlarına Etkisinin İncelenmesi*
}

\author{
An Investigation of the Effect of the Teaching of Fractions with Visual \\ Material on Primary School 4th Grade Students' Mathematics Achievement \\ and Attitudes
}

\author{
Ebru Kükey ${ }^{l}$ \\ Ahmet Melih Tutak ${ }^{2}$ \\ Tayfun Tutak ${ }^{3}$
}

Alıntılama: Kükey, E., Tutak, A. M. \& Tutak, T. (2019). Kesirler konusunun görsel materyal ile öğretiminin ilkokul 4. sınıf öğrencilerinin matematik başarı ve tutumlarına etkisinin incelenmesi. Ulusal Ĕ̆itim Akademisi Dergisi (UEAD), 3(1), 115-125.

Geliş tarihi:

26 Şubat 2019

Kabul tarihi:

23 Mart 2019

(C) UEAD 2019

Tüm

saklıdır.
Özet: Bu çalışmada, kesirler konusunun görsel materyal ile öğretiminin ilkokul 4. sınıf öğrencilerinin matematik başarı ve tutumlarını olan etkisinin incelemesi amaçlanmıştır. Çalışma nicel araştırma yöntemlerinden yarı deneysel yöntem olarak tasarlanmıştır. İlkokul 4. sınıf öğrencileriyle yapılan çalışma kapsamında deney grubunda 20, kontrol grubunda ise 18 olmak üzere 38 öğrenci ile çalışma yürütülmüştür. Veriler Kesirler Başarı Testi ve Matematik Tutum Ölçeği aracılığıyla elde edilmiştir. Ön test ve son test olarak uygulanan veri toplama araçlarıyla elde edilen veriler istatistiksel olarak analiz edilmiştir. Yapılan analizler haklarl sonucunda deney ve kontrol gruplarının veri toplama araçları son test puanları incelendiğinde, deney grubu lehine anlamlı bir farklılığın olduğu sonucuna ulaşılmıştır. Görsel materyal ile öğretimin yapıldığı deney grubunun matematik başarısının, normal öğretim yapılan kontrol grubuna göre anlamlı düzeyde arttığı belirlenmiştir. Ayrıca deney grubunun matematiğe yönelik tutumunun kontrol grubuna göre daha olumlu düzeyde olduğu sonucuna ulaşılmıştır. Buradan eğitim öğretim sürecinde tablo, resim, grafik gibi gerçek malzemeler kullanılarak oluşturulan görsel materyaller aracılığıyla yapılan öğretimin, öğrencilerin bilgileri somutlaştırmasında ve daha etkili öğrenmelerin gerçekleşmesini sağlamada etkili olacağı düşünülmektedir.

\footnotetext{
* Bu çalışma Ahmet Melih Tutak'ın yüksek lisans tez çalışmasından üretilmiştir.

${ }^{1}$ (Sorumlu yazar) Arş.Gör.Dr., Fırat Üniversitesi, Ĕ̆itim Fakültesi, Matematik ve Fen Bilimleri Ĕ̆itimi Bölümü, ekukey@firat.edu.tr, ORCID ID: 0000-0002-2130-0884.

2 Ögretmen, Milli Eğitim Bakanlı̆̆l, melihtutak@hotmail.com, ORCID ID: 0000-0002-7200-8832.

${ }^{3}$ Dr.Öğr. Üyesi, Fırat Üniversitesi, Eğitim Fakültesi, Matematik ve Fen Bilimleri Ĕ̆itimi Bölümü tayfuntutak@hotmail.com, ORCID ID:0000-0002-0277-6377.
} 
Anahtar kelimeler: kesirler, matematik öğretimi, görsel materyal.

Received:

26 February 2019

Accepted:

23 March 2019

(C) UEAD 2019

All rights reserved.

\begin{abstract}
In this study, it is aimed to examine the effect on mathematics achievement and attitudes of the 4th grade students with teaching the fractions on visual materials. The study was designed as quasi-experimental design of quantitative research methods. Within the scope of the study conducted with the 4th grade students, the study was conducted with 38 students in the experimental group and 18 in the control group. Data were obtained through Fractions Success Test and Mathematics Attitude Scale. Data obtained by pre-test and post-test data collection tools were analyzed statistically. As a result of the analysis, it was concluded that there was a significant difference in favor of the experimental group when the final test scores of the data collection tools of the experimental and control groups were examined. It was determined that the mathematics achievement of the experimental group in which visual material with teaching were performed increased significantly compared to the control group in the normal teaching. In addition, it was concluded that the experimental group's attitude towards mathematics was more positive than the control group. It is thought that teaching through visual materials created by using real materials such as tables, pictures and graphics in the teaching process will be effective in materializing the information of the students and ensuring that more effective learning is realized. Keywords: fractions, mathematics teaching, visual materials.
\end{abstract}

\section{Giriş}

Günümüzde oluşturulan eğitim öğretim programlarında bilgilerin somutlaştırılarak günlük yaşama aktarılması hedeflenmektedir. $\mathrm{Bu}$ şekilde yapılan öğretimlerin daha etkili olacağı düşünülmektedir. Matematiğin, bireyin günlük hayatlarındaki yaşanmışlıkları sonucunda edindikleri bilgileri anlamlandırmalarını ve gelişmelerini sağlayan bir bilim dalı (Baykul, 1997) olduğu göz önüne alındığında, var olan bilgilerin somutlaştırılmasının büyük önem kazandığı söylenebilir. Eğitim öğretim sürecinde yapılandırmacı yaklaşımın benimsenmesiyle öğrencilerin yalnızca belirli kaynaklardan ulaşmalarının ve bilgiyi ezberleyerek öğrenmeye çalışmalarının mümkün olmayacağı kabul edilmiştir. Öğrencilerin öğrenme sürecine aktif katılması, bilgiye nasıl ulaşılacağını araştırması ve öğrendikleri bilgileri günlük hayattaki problemlerin çözümünde etkili bir şekilde kullanabilmelerini amaçlamıştır (Kazu \& Yeşilyurt, 2008). Ayrıca öğrenme sürecinde yalnızca öğretmen ve ders kitaplarının yeterli olmadığı, etkinlikler ve öğretim materyallerinin de etkili bir yere sahip olduğu önem kazanmıştır (Alkan, 2005). Bu kapsamda matematik öğretiminde görsel materyal kullanımı ön plana çıkmaktadır.

Matematik eğitiminde görsel materyal kullanılması birçok avantaj sağlamaktadır. Kesme yapıştırma etkinlikleri, katlama etkinlikleri, yapbozlar matematik dersinde sıklıkla tercih edilen materyaller arasında bulunmaktadır. Bu materyaller, öğrencilerin derse yönelik motivasyon ve 
Kesirler Konusunun Görsel Materyal ile Öğretiminin İlkokul 4. Sınıf Öğrencilerinin Matematik Başarı ve Tutumlarına Etkisinin İncelenmesi ilgilerini arttırmanın yanında yaparak yaşayarak öğrenmelerine de imkan tanımaktadır (İnan, 2006). Bunun yanında öğretmen ve öğrencilere kavramlar üzerinde tartı̧̧alarını sağlamanın yanında, öğrencilerin daha önceden sahip oldukları kavram yanılgılarının belirlenmesi ve gerekli dönütlerin verilmesine olanak sağlar (Chin \& Teou, 2009). Görsel materyaller, soyut kavramları somutlaştırarak, karmaşık yapıları öğrencilerin daha kolay anlamasına olanak tanır (Dede \& Argün, 2003).

Literatür incelendiğinde görsel materyallerin öğrenci merkezli bir eğitim olanağı sağladığı, dersleri daha eğlenceli hale getirerek, öğrencilerin matematik başarısını olumlu yönde etkilediği sonuçlarına ulaşılmıştır (Brecht, 2000; Güngör, 2005; Kamina \& Iyer; 2009; McNeil \& Jarvin, 2007; Stokes, 2002). Matematik eğitimi sürecinde kesirler konusu okul öncesi dönemden itibaren başlamaktadır. İlkokul 1, 2 ve 3. sınıflarda aşamalı olarak öğretilmeye devam edilmekle birlikte kesirler konusunun akademik olarak öğretilmesine ilkokul 4. sınıfta geçilmektedir. Bu kapsamda yapılan bu çalışmada ilkokul 4. sınıfta kesirler konusunun görsel materyal ile öğretiminin, öğrencilerin matematik başarısı ve tutumuna etkisini incelemek amaçlanmıştır.

\section{Yöntem}

$\mathrm{Bu}$ çalışmada kesirler konusunun görsel materyalle öğretiminin ilkokul 4. sınıf öğrencilerinin matematik başarı ve tutumlarına olan etkisinin incelenmesi amaçlandığından nicel araştırma yöntemi tercih edilmiştir. Bu kapsamda, deney ile kontrol grubunun puan ortalamalarının karşılaştırılmasına dayalı yarı deneysel model kullanılmıştır. Çalışma, deney ile kontrol grubu olacak şekilde iki farklı sınıf ile yapılmıştır. Bu sınıfların ilkokul 3. sınıftaki matematik başarı puanları üzerinden yapılan analizler sonucunda, grupların başarıları arasında istatatistiksel olarak anlamlı bir farklılığın olmadığı, başarılarının birbirine yakın olduğu belirlenmiştir. Çalışmada, deney ile kontrol grubuna matematik başarı testiyle tutum ölçeği ön test olarak uygulanmış ve çalı̧̧ma sürecinde deney grubu ile kesirler konusu görsel materyal desteğiyle işlenmiştir. Kontrol grubunda ise mevcut öğretim programı ile konunun işlenmesi tamamlanmıştır.

\section{Evren ve Örneklem}

Çalışmanın evrenini, Bingöl ilindeki ilkokullarda öğrenim görmekte olan öğrenciler oluşturmaktadır. Çalışmanın örneklemi ise Bingöl ilinden alınan bir ilkokulun iki farklı şubesinde 
öğrenim görmekte olan 38 ilkokul 4. sınıf öğrencisi olarak belirlenmiştir. Bu öğrencilerden 20’si deney grubunda, 18'i ise kontrol grubunda yer alacak şekilde deney ve kontrol grupları oluşturulmuştur.

\section{Veri Toplama Araçları ve Verilerin Analizi}

Çalışmada kesirler konusunun görsel materyalle öğrenilmesinin öğrencilerin matematik başarısına etkisini görmek amacıyla matematik ders kitaplarında bulunan 20 çoktan seçmeli problemden oluşan kesirler başarı testi hazırlanmıştır. Yapılan öğretimin öğrencilerin matematiğe yönelik tutumlarına olan etkisini belirlemek amacıyla ise Milli Eğitim Bakanlığı tarafından hazırlanan İlkokul Matematik Öğretmen Kılavuz kitabında yer alan 5'li likert tipi 12 maddelik Matematik Dersine Yönelik Tutum Ölçeği Matematik Dersine Yönelik Tutum Ölçeği veri toplama aracı olarak kullanılmıştır.

Veri toplama araçları, belirlenmiş olan gruplara ön test olarak uygulanmıştır. Uygulama sonrasında yapılan analizlerde, gruplar arasında akademik başarı ve matematiğe yönelik tutumlarına yönelik olarak istatistiksel olarak farklılık bulunmamıştır. Ön test sonucunda grupların benzer olduğunun belirlenmesiyle deney grubuna 12 ders saati yani 3 hafta boyunca görsel materyaller ile öğrenci merkezli olarak kesirler konusu işlenmiştir. Kontrol grubunda ise mevcut öğretim programı ile dersin işlenmesine devam edilmiştir. Uygulamaların bitmesiyle Kesirler Başarı Testi ile Matematiğe Yönelik Tutum Ölçeği gruplara son test olarak uygulanmıştır.

Elde edilen veriler istatistiksel olarak analiz edilmiştir. Başarı testinin analizi sırasında doğru cevaplara "1" puan, boş ve yanlış cevaplara ise " 0 ” puan verilmiştir. Tutum ölçeğinin puanlanması ise hiç katılmıyorum $=1$, katılmıyorum $=2$, kararsızım=3, katılıyorum=4, tamamen katılıyorum =5 puan olacak şeklinde hesaplanmıştır. Ölçek puanlarının 11'lik puan sistemine dönüştürülmesiyle testten alınacak en yüksek puanın 100, en düşük puanın 20 olduğu tespit edilmiştir.

\section{Bulgular}

$\mathrm{Bu}$ bölümde, kesirler konusuna yönelik olarak görsel materyalle yapılan öğretimin, ilkokul 4. sınıf öğrencilerinin matematik başarı ve tutumuna etkisini incelemek amacıyla yapılan bu çalışmada elde edilen verilerin analizi ile elde edilen bulgular verilmiştir. 
Kesirler Konusunun Görsel Materyal ile Öğretiminin İlkokul 4. Sınıf Öğrencilerinin Matematik Başarı ve Tutumlarına Etkisinin İncelenmesi

\section{Görsel Materyal Kullanımının Öğrencilerin Matematik Başarısına Etkisine Yönelik}

\section{Bulgular}

Kesirler konusunun görsel materyal ile öğrenilmesinin öğrencilerin matematik başarılarına olan etkisini belirleyebilmek için ilk olarak uygulamadan önce gruplar arasında istatistiksel olarak anlamlı bir farklılı̆̆ın olup olmadığını tespit edebilmek amacıyla deney ve kontrol grubuna Kesirler Başarı Testi uygulanmıştır. Elde edilen verilerin analizi ile aşağıdaki bulgulara ulaşılmıştır.

Tablo 1. Grupların Ön Test Puanlarına Yönelik Bulgular

\begin{tabular}{lccccc}
\hline Gruplar & $\mathrm{N}$ & Sira Ortalamas1 & Sira Toplamı & $\mathrm{U}$ & $\mathrm{p}$ \\
\hline Deney & 20 & 20.45 & 409.00 & \multirow{2}{*}{161.000} & .569 \\
Kontrol & 18 & 18.44 & 332.00 & & \\
\hline
\end{tabular}

Grupların Kesirler Başarı Testi ön test başarı puanları karşılaştırıldığında $p>.05$ olduğu belirlenmiştir. Bu durum, deney ile kontrol grubunun kesirler konusundaki ön bilgileri arasında anlamlı bir farklılığın olmadığını ve grupların başarı düzeylerinin birbirine benzer olduğunu göstermektedir. Deney grubunun ön test ile son test başarı puanlarından elde edilen bulgular aşağıda verilmiş̧tir.

Tablo 2. Deney Grubunun Ön Test ile Son Test Puanlarına Yönelik Bulgular

\begin{tabular}{lccccc}
\hline Son test - Ön test & $\mathrm{N}$ & Sira Ortalaması & Sıra Toplamı & $\mathrm{Z}$ & $\mathrm{p}$ \\
\hline Negatif Sıra & 0 & .00 & .00 & & \\
Pozitif Sıra & 19 & 10.00 & 190.00 & -3.834 & .000 \\
Eşit & 1 & & & & \\
\hline
\end{tabular}

Deney grubunun uygulama öncesi ve sonrasında almış oldukları başarı puanları karşılaştırıldığında $\mathrm{p}<.05$ olduğu tespit edilmiştir. İki test arasında istatistiksel olarak anlamlı bir farkl11ı̆̆ın olduğu görülmüş ve bu farklılğın son test lehine olduğu belirlenmiştir. Buradan kesirler konusunun görsel materyal ile öğretilmesinin öğrencilerin matematik başarısını olumlu yönde etkilediği ifade edilebilir. Kontrol grubunun ön test ve son test başarı puanlarından elde edilen bulgular ise aşağıda verilmiştir.

Tablo 3. Kontrol Grubunun Ön Test ile Son Test Puanlarına Yönelik Bulgular

\begin{tabular}{lccccc}
\hline Son test - Ön test & $\mathrm{N}$ & Sıra Ortalaması & Sıra Toplamı & $\mathrm{Z}$ & $\mathrm{p}$ \\
\hline Negatif Sıra & 0 & .00 & .00 & & \\
Pozitif Sıra & 18 & 9.50 & 171.00 & -3.749 & .000 \\
Eşit & 0 & & & & \\
\hline
\end{tabular}


Kontrol grubunun uygulamadan önce ve uygulama sonrasında almış oldukları başarı puanları karşılaştırıldığında $\mathrm{p}<.05$ olduğu görülmektedir. İki test arasında istatistiksel olarak anlamlı bir farklılığın olduğu belirlenmiş ve bu farklılığın son test lehine olduğu tespit edilmiştir. Buradan kontrol grubunda uygulanan öğretimin öğrencilerin başarılarını arttırmada etkili olduğu belirlenmiştir. Gruplarının Kesirler Başarı Testi son test puanlarının karşılaştırılmasıyla aşağıdaki bulgular elde edilmiştir.

Tablo 4. Grupların Son Test Puanlarına Yönelik Bulgular

\begin{tabular}{lccccc}
\hline Gruplar & $\mathrm{N}$ & Sira Ortalamas1 & Sira Toplamı & $\mathrm{U}$ & $\mathrm{p}$ \\
\hline Deney & 20 & 24.38 & 487.50 & \multirow{2}{*}{82.500} & \multirow{2}{*}{004} \\
Kontrol & 18 & 14.08 & 253.50 & \\
\hline
\end{tabular}

Deney ile kontrol grubunun puanları karşılaştırıldığında $\mathrm{p}<.05$ olarak belirlenmiştir. Buradan grupların son test puanları arasında istatistiksel olarak anlamlı bir farklılığın olduğu tespit edilmiş ve bu farkın deney grubu lehine olduğu görülmüştür. Dolayısıyla, görsel materyal destekli olarak öğretimin yapıldığı deney grubunun kontrol grubuna göre anlamlı olarak daha başarılı olduğu tespit edilmiştir. $\mathrm{Bu}$ kapsamda kesirler konusunun görsel materyal ile öğretilmesinin öğrencilerin başarılarını artırmada mevcut öğretim programına göre daha etkili olduğu belirlenmiştir.

\section{Görsel Materyal Kullanımının Öğrencilerin Matematik Tutumuna Etkisine Yönelik}

\section{Bulgular}

Kesirler konusunun öğrenilmesinde görsel materyal kullanılmasının, öğrencilerin matematiğe yönelik tutumlarına etkisini belirlemek amacıyla gruplara ön test olarak uygulanan Matematiğe Yönelik Tutum Ölçeği’nden elde edilen veriler aşağıdaki verilmiştir.

Tablo 5. Grupların Ön Test Puanlarına Yönelik Bulgular

\begin{tabular}{lccccc}
\hline Gruplar & $\mathrm{N}$ & Sira Ortalamas1 & Sira Toplamı & $\mathrm{U}$ & $\mathrm{p}$ \\
\hline Deney & 20 & 20.00 & 400.00 & 170.000 & .768 \\
Kontrol & 18 & 18.94 & 341.00 & & \\
\hline
\end{tabular}

Deney ve kontrol grubunun ölçek puanları karşılaştırıldığında p>.05 bulunmasıyla grupların puanları arasında anlamlı yönde bir farklılı̆̆ın olmadığı belirlenmiştir. Buradan uygulama yapılmadan önce grupların matematiğe yönelik tutumlarının benzer olduğu ifade 
Kesirler Konusunun Görsel Materyal ile Öğretiminin İlkokul 4. Sınıf Öğrencilerinin Matematik Başarı ve Tutumlarına Etkisinin İncelenmesi edilebilir. Deney grubunun tutum ölçeğine yönelik ön test ile son test puanlarına ilişkin bulgular aşağıda verilmiştir.

Tablo 6. Deney Grubunun Ön Test ile Son Test Puanlarına Yönelik Bulgular

\begin{tabular}{lccccc}
\hline Son test - Ön test & $\mathrm{N}$ & Sıra Ortalaması & Sıra Toplamı & $\mathrm{Z}$ & $\mathrm{P}$ \\
\hline Negatif Sıra & 2 & 2.25 & 4.50 & & \\
Pozitif Sıra & 16 & 10.41 & 166.50 & -3.533 & .000 \\
Eşit & 2 & & & & \\
\hline
\end{tabular}

Deney grubunun ölçeğe yönelik almış olduğu puanlar karşılaştıııldığında $p<.05$ olarak belirlenmiştir. $\mathrm{Bu}$ durum deney grubunun puanları arasında anlamlı yönde bir farklılığın olduğunu göstermektedir. Bu farklılığın ise son test lehine gerçekleștiği belirlenmiştir Kesirler konusunun görsel materyal kullanılarak öğretiminin, öğrencilerin matematik dersine karş1 tutumlarını olumlu yönde etkilediği tespit edilmiştir. Kontrol grubunun, tutum ölçeği ön test ve son test puanlarına yönelik bulgular ise aşağıda verilmiştir.

Tablo 7. Kontrol Grubunun Ön Test ile Son Test Puanlarına Yönelik Bulgular

\begin{tabular}{lccccc}
\hline Son Test - Ön Test & $\mathrm{N}$ & Sira Ortalaması & Sira Toplamı & $\mathrm{Z}$ & $\mathrm{p}$ \\
\hline Negatif Sıra & 5 & 6.70 & 33.50 & & \\
Pozitif Sıra & 11 & 9.32 & 102.50 & -1.786 & 0.074 \\
Eşit & 2 & & & & \\
\hline
\end{tabular}

Kontrol grubunun tutum ölçeğine yönelik almış olduğu puanlar karşılaştırıldığında p >.05 olduğu tespit edilmiştir ve bu durum kontrol grubunun test puanları arasında anlamlı yönde bir farklılığın olmadığı şeklinde ifade edilebilir. Buradan kontrol grubunda yapılan öğretimin öğrencilerin matematiğe yönelik tutumlarını etkilemediği söylenebilir. Grupların tutum ölçeği son test puanlarına yönelik bulgular aşağıda verilmiştir.

Tablo 8. Gruplarin Son Test Puanlarina Yönelik Bulgular

\begin{tabular}{lccccc}
\hline Gruplar & $\mathrm{N}$ & Sira Ortalamas1 & Sira Toplamı & $\mathrm{U}$ & $\mathrm{p}$ \\
\hline Deney & 20 & 24.55 & 491.00 & 79.000 & \multirow{2}{*}{.003} \\
Kontrol & 18 & 13.89 & 250.00 & \multirow{2}{*}{} \\
\hline
\end{tabular}

Grupların Matematiğe Yönelik Tutum Ölçeği son test puanları karşılaştırıldığında $\mathrm{p}<.05$ olduğu tespit edilmiştir. Bu durum gruplar arasında deney grubu lehine istatistiksel olarak anlamlı bir farklılık olduğunu göstermektedir. Buradan deney grubunda görsel materyal destekli yapılan 
öğretimin kontrol grubunda yapılan öğretime göre öğrencilerin matematiğe yönelik tutumlarını arttırmada oldukça etkili olduğunu söylenebilir.

\section{Sonuç Tartışma ve Öneriler}

Yapılan bu çalışmada görsel materyalle yapılan öğretimin ilkokul 4. sınıf öğrencilerinin kesirler konusuna yönelik başarılarına ve matematiğe yönelik tutumlarına olan etkisi incelenmiştir. Bu kapsamda Kesirler Başarı Testi ile Matematiğe Yönelik Tutum Ölçeği kullanılmıştır.

Çalışmada deney ve kontrol grubunun matematik başarılarını belirlemek amacıyla yapılan ön test ile gruplar arasında anlamlı bir farklılığın olmadığı ve grupların uygulama yapılmadan önce başarılarının benzer düzeyde olduğu belirlenmiştir. Kontrol grubunun matematik başarılarına yönelik olarak ön test ile son test puanları incelendiğinde, son test puanlarının daha yüksek olduğu belirlenmiştir. Benzer şekilde deney grubunun matematik başarılarına yönelik olarak ön testle son test puanları arasında da son test lehine anlamlı bir farklılığın olduğu sonucuna ulaşılmıştır. Grupların son test puanları karşılaştırıldığında ise deney grubunun matematik başarının kontrol grubuna göre anlamlı olarak daha yüksek düzeyde olduğu tespit edilmiştir. Bu durum grupların son test puanlarının ön test puanlarına göre daha yüksek olmasına rağmen, son test puanları incelendiğinde deney grubunun daha yüksek düzeyde olduğu görülmüştür. Buradan kesirler konusunun öğretiminde, görsel materyalle yapılan öğretimin mevcut öğretime programına göre daha etkili olduğu ve öğrencilerin başarılarını daha da arttırdığı sonucuna ulaşılmıştır. Benzer şekilde Körükçü (2008) çalışmasında görsel materyal kullanımın tam sayılar konusunun öğretimi üzerindeki etkisini incelemiştir. Bu kapsamda deney ile kontrol gruplarının son test puanları arasında deney grubu lehine anlamlı bir farklılığın olduğunu tespit etmiştir. Sarı (2010) ise somut materyalle yapılan öğretimin ilkokul 4. sınıf öğrencilerinin geometri başarılarına olan etkisini incelemiş ve somut materyallerin öğrencilerin başarılarını arttırdığını belirlemiştir. Benzer şekilde yapılan çalışmalarda görsel materyal kullanımının öğrencilerin matematik başarısını arttırdığı sonucuna ulaşılmıştır (Brecht, 2000; Hiebert, Wearne \& Taber, 1991; Kamii \& Lewis, 1990; Karaduman, 2005). Buradan eğitim öğretim sürecinde tablo, resim, grafik gibi gerçek malzemeler kullanılarak yapılan görsel materyallerin, öğrencilerin bilgileri somutlaştırdığı ve daha etkili öğrenmelerin gerçekleşmesini sağladığı düşünülmektedir. 
Kesirler Konusunun Görsel Materyal ile Öğretiminin İlkokul 4. Sınıf Öğrencilerinin Matematik Başarı ve Tutumlarına Etkisinin İncelenmesi

Çalışmada deney ile kontrol gruplarının matematiğe yönelik tutumlarını belirlemek amacıyla yapılan ön test puanları incelendiğinde gruplarının birbirleriyle benzer tutuma sahip oldukları belirlenmiştir. Kontrol grubunun ön test ile son test puanları incelendiğinde, puanlar arasında anlamlı bir farklılığın olmadığı belirlenmiştir. Buradan kontrol grubunda yapılan öğretimin, öğrencilerin matematiğe yönelik tutumlarını anlamlı yönde etkilemediği sonucuna ulaşılmıştır. Bu durumla benzer olarak Körükçü (2008) görsel materyal üzerine yapmış olduğu çalışmasında, kontrol grubunun matematiğe yönelik tutumlarının ön test ile son test puanları arasında anlamlı bir farklılığın olmadığı sonucuna ulaşmıştır. Deney grubunun ön testle son test puanları incelendiğinde ise son test puanlarının anlamlı düzeyde daha yüksek olduğu tespit edilmiştir. Aynı zamanda grupların son test puanları karşılaştırıldığında deney grubunun tutum puanının kontrol grubuna göre anlamlı düzeyde daha yüksek olduğu görülmüştür. Buradan görsel materyallerle yapılan matematik öğretiminin, öğrencilerin matematiğe yönelik tutumlarını olumlu yönde etkilediği sonucuna ulaşılmıştır. Yapılan çalışmalarda görsel materyal kullanımının matematiğe yönelik tutumu olumlu olarak etkilediği belirlenmiştir (Castro, 1998; McNeil \& Jarvin, 2007; Patricia, 2001).

Sonuç olarak görsel materyallerle yapılan öğretimin, bilgilerin daha etkili bir şekilde öğrenilmesini ve matematiğe yönelik tutumu olumlu olarak etkilediği ifade edilebilir. Soyut kavramlardan oluşan matematik konularının görsel materyallerle desteklenerek işlenmesinin kalıcı öğrenmelerin sağlanmasında oldukça etkili olduğu düşünülmektedir. Matematik öğretiminde görsel materyal kullanılması öğrencilerin öğrenmelerini kolaylaştırdığı, somut deneyimler yaşamalarını ve derse aktif katılmalarını sağladığı görülmüştür. Bu şekilde yapılan öğretimin, kalıcı öğrenmelerin gerçekleşmesini ve dersi eğlenceli hale getirerek matematiğe yönelik tutumu olumlu yönde etkilediği ifade edilebilir. Kesirler konusu da soyut kavramlardan oluşması nedeniyle görsel materyallerle konunun öğretilmesinin öğrencilerin matematik başarılarını arttırdığı ve tutumlarını olumlu yönde etkilediği sonucuna ulaşılmıştır.

\section{Kaynakça}

Alkan, C. (2005). Eğitim teknolojisi. Ankara: Anı yayınc1lık.

Baykul, Y. (1997). Illköğretimde matematik öğretimi. Ankara: Anı yayınc1lık.

Brecht, L. J. (2000). The relative effects of cooperative learning, manipulatives, and the combination of cooperative learning and manipulatives on fourth graders' conceptual 
knowledge, computation knowledge, and problem solving skills in multiplication. Dissertation Abstracts International.

Castro, C. S. (1998). Teaching probability for conceptual change. Educational Studies in Mathematic, 35, 233-254.

Chin, C. \& Teou, L. Y. (2009). Using concept cartoons in formative assessment: Scaffolding students' argumentation. International Journal of Science Education, 31(10), 1307 - 1332.

Dede, Y. \& Argün, Z. (2003). Matematik öğretiminde elektronik tabloların kullanımı. Pamukkale Üniversitesi Eğitim Fakültesi Dergisi, 2(14), 113-131.

Güngör, S. (2005). Ortaöğretim geometri dersi üçgenler konusunda oluşsturmacı yaklaşıma dayalı elle yapılan materyaller ve portfolyo hazırlamanın öğrenciler üzerindeki etkilerinin incelenmesi. Yayımlanmamış Yüksek Lisans Tezi, Zonguldak Karaelmas Üniversitesi Sosyal Bilimler Enstitüsü, Zonguldak.

Hiebert, J., Wearne D., \& Taber, S. (1991). Fourth graders' gradual construction of decimal fractions during instruction using different physical representations. The Elementary School Journal, 91(4), 321-341.

İnan, C. (2006). Matematik öğretiminde materyal geliştirme ve kullanma. Dicle Üniversitesi Ziya Gökalp Eğitim Fakültesi Dergisi 7, 47-56.

Kamii, C. \& Lewis, B. A. (1990). Constructivism and first grade arithmetic. Arithmetic Teacher, 38(1), 34-35.

Kamina, P. \& Iyer, N. N. (2009). From concrete to abstract: Teaching for transfer of learning when using manipulatives. NERA Conference Proceedings 2009 Northeastern Educational Research Association (NERA) Annual Conference.

Karaduman, H. (2005). Sosyal bilgiler dersinde yapılandırmacı öğrenme ilkelerine göre hazırlanan öğretim materyallerinin öğrencilerin derse ilişkin tutumlarına, başarılarına ve hatırlama düzeylerine etkisi. Yayınlanmış Yüksek Lisans Tezi, Anadolu Üniversitesi, Eğitim Bilimleri Enstitüsü, Eskişehir.

Kazu, H. \& Yeşilyurt, E. (2008). Öğretmenlerin öğretim araç-gereçlerini kullanım amaçları. Fırat Üniversitesi Sosyal Bilimler Dergisi, 18(2), 175-188.

Körükçü, E. (2008). Tam sayılar konusunun görsel materyal ile ögreniminin 6. sınıf öğrencilerinin matematik başarılarına etkisi, Yayımlanmamış Yüksek Lisans Tezi, Marmara Üniversitesi, Eğitim Bilimleri Enstitüsü, İstanbul. 
Kesirler Konusunun Görsel Materyal ile Öğretiminin İlkokul 4. Sınıf Öğrencilerinin Matematik Başarı ve Tutumlarına Etkisinin İncelenmesi

McNeil, N. M. \& Jarvin, L. (2007). When theories don't add up: Disentangling the manipulatives debate. Theory into Practice, 46(4), 309-316.

Patricia, S. M. (2001). Are we having fun yet? How teachers use manipulatives to teach mathematics. Educational Studies in Mathematic, 47, 175-197.

Sar1, S. (2010). The effect of instruction with concrete materials on fourth grade students' geometry achievement. Unpublished master's thesis. Middle East Technical University, Ankara.

Stokes, S. (2002). Visual literacy in teaching and learning: A literature perspective. Electronic Journal for the Integration of Technology in Education, 1(1), 10-19. 